\title{
ANALISIS FRAMING KASUS DALAM BINGKAI MEDIA ONLINE CNN INDONESIA DAN REPUBLIKA.CO.ID
}

\author{
Ernani $^{1)}$ Silvia Noviana ${ }^{2)}$ \\ 1) 2 Program Studi Pendidikan Bahasa Indonesia \\ Universitas Islam Ogan Komering Ilir Kayuagung \\ ${ }^{1)}$ ernaniali121282@gmai.com ${ }^{2)}$ silvianoviana376@gmail.com
}

\begin{abstract}
Abstrak
Penelitian ini bertujuan untuk mendeskripsikan analisis framing yang meliputi sintaksis, skrip, tematik, retoris kasus LGBT dalam media online CNN Indonesia dan Republika.co.id. Metode yang digunakan ialah deksriptif kualitatif.Media yang digunakan untuk menganalisis dalam penelitian ini yaitu media online Republika.co.id dan CNN Indonesa pada periode Januari-Maret 2020.Keseluruhan berita yang dianalisis dari kedua media berjumlah 20 berita. Penentuan berita yang diteliti terdapat tiga tema yaitu pemerintah kota, HAM, dan Agama. Pada penelitian ini menggunakan Analisis Framing Zhongdang Pan dan Gerald M. kosicki terdapat empat struktur yaitu sintaksis, skrip, tematik, retoris. Hasil yang didapat pada penelitian dari kedua media online tersebut memiliki cara pembingkaian yang berbeda seperti, media online Republika.co.id yang bersikap tegas dalam menolak kelompok LGBT dengan berdasarkan ajaran Islam berbeda dengan CNN Indonesia cenderung bersikap netral terhadap kelompok LGBT.
\end{abstract}

Kata kunci: framing, pembelajaran

\section{PENDAHULUAN}

Fenomena LGBT berawal dari

Negara Barat yang melegalkan komunitas ini, bahkan di masyarakat tersebut sudah bukan hal yang tabu dan tidak bertentangan dengan moral apalagi kepincangan seksual. Lain halnya di Indonesia, keberadaan kaum ini belum bisa diterima karena bertentangan bukan hanya berkaitan moralitas suatu bangsa, tetapi bertentangan dengan agama yang mayoritas dianut di Negara Indonesia.
Era modern dan serba teknologi digital menjadi keuntungan tersendiri bagi masyarakat khususnya ketika menyerap informasi yang berhubungan berbagai bidang ilmu salah satunya berita Lesbian, Gay, Biseksual, dan Transgender. Hal tersebut perlu mendapat perhatian publik ataupun setiap orang yang memiliki atau berada di antara lingkaran geng LGBT ini. Kita tidak perlu menjauhi, tetapi memberikan pendidikan moral dan menguatkan 
akidah mereka supaya tidak larut dalam pemaknaan cinta yang salah.

Penelitian ini sangat berguna dilaksanakan untuk mengetahui seperti apa sudut pandang dari media mengenai sebuah peristiwa dengan menggunakan struktur dari teori Zhongdang Pan dan Gerald M Kosicki, yakni sintaksis, skrip, tematik, dan retoris. Halik (2013, h. 22) menyatakan komunikasi massa bisa dilihat melalui dua sudut pandang, yaitu bagaimana orang menghasilkan pesan dan menyebarkannya melalui media, serta bagaimana cara mencari dan menggunakan pesan-pesan tersebut di pihak lainnya.

Dalam teori paradigma konstruksionis dipaparkan bagaimana bingkai dan konstruksi wacana dalam jurnalistik. Seperti halnya pendapat Eriyanto (2002, h. 15) bahwa paradigma konstruksionis pertama kali dikemukakan oleh sosiolog interpretatif Peter L. Berger bersama Thomas Luckman. Di mana banyak menulis karya dan menghasilkan tesis mengenai konstruksi sosial atas realitas.
Analisis framing termasuk model analisis alternatif yang membuka rahasia dibalik perbedaan setiap media massa, yaitu dalam pengungkapan fakta. Analisis ini membongkar bagaimana realitas tersebut dibingkai dalam balutan kata-kata yang menarik pembaca.

Dari beberapa model analisis framing, model Zhongdang Pan dan Gerald M. Kosicki adalah salah satu model yang paling populer dan sering digunakan dalam penelitian deskriptif kualitatif., Dalam model framing Pan Kosicki, perangkat framing dapat dibagi ke dalam empat struktur besar seperti telah dijelaskan sebelumnya (dalam Irmawan, 2015, h. 40).

Lain halnya dengan Pramudya (2017, h. 30-32) mengistilahkan LGBT lebih ke orientasi wanita menyukai teman sejenisnya secara fisik, seksual, emosional atau spiritual dan sering disebut lesbi. Sebalikya, laki-laki yang mencintai sesamanya dinamakan gay. Homoseksual kelompok ini mempunyai keinginan dan rasa cinta selayaknya pasangan normal lainnya. Selanjutnya, biseksual berorientasi 
tertarik kepada fisik dan romantisme keduanya, yakni pria dengan pria, wanita dengan wanita. Setelah itu, laki-laki yang penyuka sejenis pun melakukan aktivitas seksual dengan perempuan penyuka perempuan, demikian pula sebalinya. oknum pengidap biseksual akan menghadapi permasalahan dengan kumpulan homofobia, tetapi konflik itu bukan gejala gangguan kepribadian. Sementara itu, istilah transgender ialah meliputi banyak orang dengan identitas yang khusus. Artinya, seseorang beridentitas ini memiliki gender dengan jenis kelamin berbeda secara biologis.

\section{METODE PENELITIAN}

Penelitian ini menggunakan pendekatan kualitatif dengan jenis Intetpretatif, dengan metode deskriptif kualitatif. Sumber data yang dipakai ialah primer dan sekunder. Proses mengumpulkan data yang dilakukan memiliki cara atau teknik untuk mendapatkan data secara terstruktur dan akurat supaya dapat dipertanggung jawabkan. Caranya melakukan observasi, dokumentasi, serta menganalisis teks.

\section{PEMBAHASAN}

Hasil dari analisis framing yang telah dilakukan oleh peneliti melalui media online CNN Indonesia dan Republika.co.id yang berfungsi sebagai infrormasi berita yang ditulis oleh wartawan untuk mengetahui bagaimana kedua media tersebut membingkai sebuah berita tentang LGBT karena jika dilihat secara umum kedua media tersebut sudah terlihat memiliki perbedaan yaitu CNN Indonesia yang memberitakan tentang LGBT lebih bersifat netral sedangkan Republika.co.id bersifat tegas dalam menolak keberadaan LGBT.

Hasil dari analisis framing yang telah dilakukan oleh peneliti melalui media online CNN Indonesia dan Republika.co.id yang berfungsi sebagai infrormasi berita yang ditulis oleh wartawan untuk mengetahui bagaimana kedua media tersebut membingkai sebuah berita tentang LGBT karena jika dilihat secara umum kedua media tersebut sudah terlihat memiliki perbedaan yaitu 
CNN Indonesia yang memberitakan tentang LGBT lebih bersifat netral sedangkan Republika.co.id bersifat tegas dalam menolak keberadaan LGBT.

1) Struktur Sintaksis, pada berita yang dimuat disitus CNN Indonesia pada setiap beritanya memperlihatkan pro dan kontra terhadap keberadan LGBT. Dalam hal ini pihak Pemerintah kota Depok yang menjadi pihak kontra LGBT yang memberikan tanggapan negatif pada keberadaan LGBT sementara pihak pro yaitu dari pihak Komnas HAM, sedangkan pada media Republika.co.id sangat jelas mempelihatkan penolakan terhadap keberadaan LGBT pada tiap-tiap beritanya berlandasakan ajaran agama khususnya islam.

2) Struktur Skrip, pada kedua media tersebut media $\mathrm{CNN}$ Indonesia dan Republika. Co. Id sudah memperlihatkan kelengkapan $5 \mathrm{~W}+1 \mathrm{H}$, akan tetapi teks dari berita pada media CNN Indonesia tampak lebh padat dan cermat dalam menyusun informasi di dalam berita, sementara pada media Republika.co.id seolah terbatas dan berfokus pada komentar narasumber.

3) Struktur Tematik, pada struktur tematik pada media online $\mathrm{CNN}$ Indonesia dan Republika.co.id ini seluruh berita dari kedua media online tersebut bahwa keduanya sama memuat pernyataan dan pendapat dari nararumber mengenai kasus LGBT. Akan tetapi pada media online Republika.co.id hanya sedikit menuliskan berita secara lengkap berdasakan sumbersumber yang akan memperkuat informasi di dalam berita. Berbeda halnya dengan CNN Indonesia yang memasukkan sumber-sumber lain dalam berita mengenai kasus LGBT agar dapat memperkuat informasi di dalam berita.

4) Struktur Retoris, media online CNN Indonesia dan Republika.co.id, kedua media online tersebut sama-sama lebih menekankan pada elemen leksikon dan grafis dalam 
pembingkaian berita. Dari hasil analisis berdasarkan struktur retoris media CNN Indonesia lebih berupaya menyesuaikan gambar atau foto sesuai dengan tema yang diberitakan, berbeda halnya dengan Republika.co.id dalam menekankan elemen gambar atau foto hanya beberapa berita yang sesuai dengan tema, pada media ini lebih banyak menggunakan gambar ilustrasi tentang LGBT. Adapun pandangan mengenai LGBT dari segi psikologi dan sosial, yaitu:

1. Psikologi

a) Dari segi psikologis memiliki dukungan yang sangat kuat, dikarnakan baik dari mental maupun biologis, dianggap bukanlah sebagai penyakit maupun penyimpangan, melainkan sesuatu anugrah dari lahir. Namun, bisa juga dibentuk karena faktor pergaulan tetapi, pengaruh tersebut tidak berimbas secara instan, melainkan bertahun-tahun. b) Ada beberapa dari pihak yang menentang keras LGBT, alasannya aktivitas dari kaum ini dapat mengancam keberlangungan keturunan umat manusia, serta merusak tatanan alam.

2. Segi Sosial

a) Dalam segi sosial khususnya di indonesia, mayoritas masyarakat sangat menentang keras seluruh aktifitas LGBT. Hal itu disebabkan bertentangan dengan tradisi, budaya, dan agama. Sehingga membuat masyarakat tidak setuju dan merasa bingung akan pemahaman dari kaum LGBT. Terutama pada kaum gay, lesbi, dan biseksual tidak mencontohkan budaya Indonesia yang menonjolkan nilai-nilai Ketuhanan Yang Maha Esa.

b) Dari segi sosial agama, seluruh agama yang diakui oleh negara indonesia sangat menolak keberadaan kaum lesbi, gay dan 
biseksual, dan transgender bahkan banyak yang memberi ancaman keras kepada kaum-kaum tersebut, seperti terjadi di Depok dan Sumatra Barat.

c) Namun untuk kaum transgender, masyarakat Indonesia terlihat tidak terlalu mengecam keras dibandingkan dengan kaum Lesbi, gay dan biseksual, kaum transgender dianggap bukan lah sebagai penyimpangan seksual, tetapi lebih dianggap sebagai seseorang yang cacat fisik, sehingga harus berganti kelamin agar dapat hidup normal seperti masyarakat lainnya.

d) Meskipun kaum transgender tidak dapat penolakan keras dimasyarat, tetap saja mereka mendapat perlakuan yang berbeda dalam bermasyarakat kaum transgender tidak begitu dilibatkan untuk memimpin dalam acara-acara seperti acara adat dan agama, disebakan adanya keraguan

di hati mayarakat.

\section{SIMPULAN}

Berdasakan hasil analisis berita dari media elektorinik CNN Indonesia dan Republika.co.id. didapatkanlah duapuluh berita yang dianalisis. Sepuluh berita dari media online CNN Indonesia dan sepuluh berita dari media online Republika.co.id. Batas periode pengambilan berita tersebut mulai yaitu Januari sampai Maret 2020. Jika dilihat dan dibandingkan secara umum kedua media online tersebut terlihat jelas perbedaannya. Pada media online CNN Indonesia dalam menyampaikan informasi masih bersikap netral. Berita yang ditulis oleh media CNN Indonesia tidak semuanya menolak LGBT dengan tegas, seperti terdapat beberapa berita yang cenderung netral dan bahkan lebih ke pro dengan keberadaan LGBT. Misalnya berita yang berjudul : "Amnesty International: Razia LGBT di Depok Tak Manusiawi”, dari berita tersebut, terlihat dukungan dari direktur Amnesty International yaitu Usman 
Hamid dan mengatasnamakan HAM, karena menurutnya adanya razia tersebut sudah merupakan tindakan kebencian dan diskriminatif.Berbeda halnya dengan media online Republika.co.id, pada setiap beritanya menegaskan bahwa LGBT dilarang dan banyak juga masyarakat yang menolak keberadaan LGBT.Media ini juga menegaskan bahwa LGBT dapat merusak baik agama, moral, budaya, keluarga, bahkan bangsa. Salah satunya berita yang berjudul : "Demo Tolak LGBT dan Kecam Intervensi Komnas HAM di Depok".

Hasil analisis ini diharapkan dapat berimplikasi dalam pembelajaran Bahasa Indonesia di SMP. Selain itu, juga dapat meningkatkan minat baca siswa dalam membaca berita karena pada dasarnya dengan membaca berita siswa juga akan mendapatkan banyak wawasan salah satunya pemahaman mengenai LGBT.

\section{DAFTAR PUSTAKA}

CNN Indonesia.(2020). Berita LGBT. https//m.cnnindonesia.com/tag/ lgbt. Diakses Januari-Maret 2020.
Eriyanto.(2002). Analisis framing. Yogyakarta: Lkis.

Halik, Abdul. (2013). Komunikasi massa. Makasar: AU Press.

Irmawan, Rama. (2015). Analisis framing penangkapan bambang widjojanto pada media online tempo.co dan media indonesia.com. Skripsi S1.Yogyakarta. Universitas Islam Negeri Sunan Kalijaga.(Online)

Kompas.com. (2015).Mahkamah agung amerika serikat legalkan

LGBT.https://internasional.kom pas.com/read/2015/06/26/2307 3761/Mahkamah.Agung.Ameri ka.legalkan.pernikahan.sesama. jenis. Diakses 21 februari 2020.

Kompas.com. (2019).Bagaimana idealnya media memberitakan LGBT.https://lifestyle.kompas. com $/ \mathrm{read} / 2019 / 01 / 28 / 1102079$ 20/bagaimana-idealnya-mediamemberitakan-isu-lgbt-

?page $=$ all. Diakses5Agustus $\underline{2020}$

Pramudya, Riski, A. (2017). LGBT (Lesbian, Gay, Biseksual, Transgender) dalam pandangan pendidik muslim. Skripsi S1. Yogyakarta.Universitas Islam Negeri Sunan Kalijaga.(Online) Republika.(2020). Berita LGBT.https://m.republika.co.id /tag/lgbt. Diakses januari-maret 2020.

USAID \& UNDP, (2019).Hidup

sebagai LGBT di asia laporan

nasional

indonesia.https://www.usaid.gov/site s/default/files/document/2496/Being 
Ernani, Silvia Noviana

_LGBT_in_Asia_Indoonesia_Countr $\quad$ y_Report_Bahasa_language.pdf 